\title{
Targeting fibroblast activation protein in newly diagnosed squamous cell carcinoma of the oral cavity - initial experience and comparison to $\left[{ }^{18} \mathrm{~F}\right] \mathrm{FDG}$ PET/CT and MRI
}

\author{
Christian Linz ${ }^{1,2} \cdot$ Roman C. Brands ${ }^{1,2} \cdot$ Olivia Kertels $s^{2,3} \cdot$ Alexander Dierks $s^{2,4,5} \cdot$ Joachim Brumberg ${ }^{2,4,6}$. \\ Elena Gerhard-Hartmann ${ }^{2,7}$. Stefan Hartmann ${ }^{1}$. Andreas Schirbel ${ }^{2,4}$. Sebastian Serfling ${ }^{2,4}$. Yingjun Zhi ${ }^{8}$. \\ Andreas K. Buck ${ }^{2,4} \cdot$ Alexander Kübler ${ }^{1,2} \cdot$ Julian Hohm ${ }^{1}$. Constantin Lapa ${ }^{2,4,5}$ (I) Malte Kircher ${ }^{2,4,5}$ (D)
}

Received: 3 February 2021 / Accepted: 19 May 2021 / Published online: 29 May 2021

(c) The Author(s) 2021

\begin{abstract}
Purpose While $\left[{ }^{18} \mathrm{~F}\right]$-fluorodeoxyglucose $\left(\left[{ }^{18} \mathrm{~F}\right] \mathrm{FDG}\right)$ is the standard for positron emission tomography/computed tomography (PET/CT) imaging of oral squamous cell carcinoma (OSCC), diagnostic specificity is hampered by uptake in inflammatory cells such as neutrophils or macrophages. Recently, molecular imaging probes targeting fibroblast activation protein $\alpha(\mathrm{FAP})$, which is overexpressed in a variety of cancer-associated fibroblasts, have become available and might constitute a feasible alternative to FDG PET/CT.

Methods Ten consecutive, treatment-naïve patients ( 8 males, 2 females; mean age, $62 \pm 9$ years) with biopsy-proven OSCC underwent both whole-body $\left[{ }^{18} \mathrm{~F}\right] \mathrm{FDG}$ and $\left[{ }^{68} \mathrm{Ga}\right] \mathrm{FAPI}-04$ (FAP-directed) PET/CT for primary staging prior to tumor resection and cervical lymph node dissection. Detection of the primary tumor, as well as the presence and number of lymph node and distant metastases was analysed. Intensity of tracer accumulation was assessed by means of maximum $\left(\mathrm{SUV}_{\mathrm{max}}\right)$ and peak $\left(\mathrm{SUV}_{\text {peak }}\right)$ standardized uptake values. Histological work-up including immunohistochemical staining for FAP served as standard of reference.

Results $\left[{ }^{18} \mathrm{~F}\right] \mathrm{FDG}$ and FAP-directed PET/CT detected all primary tumors with a SUV max $_{\text {of }}$ of $25.5 \pm 13.2$ (FDG) and $20.5 \pm 6.4$ (FAP-directed) and a SUV ${ }_{\text {peak }}$ of $16.1 \pm 10.3\left(\left[{ }^{18} \mathrm{~F}\right] \mathrm{FDG}\right)$ and $13.8 \pm 3.9$ (FAP-directed), respectively. Regarding cervical lymph node metastases, FAP-directed PET/CT demonstrated comparable sensitivity $(81.3 \%$ vs. $87.5 \% ; P=0.32)$ and specificity $(93.3 \%$ vs. $81.3 \% ; P=0.16)$ to $\left[{ }^{18} \mathrm{~F}\right]$ FDG PET/CT. FAP expression on the cell surface of cancer-associated fibroblasts in both primary lesions as well as lymph nodes metastases was confirmed in all samples.

Conclusion FAP-directed PET/CT in OSCC seems feasible. Future research to investigate its potential to improve patient staging is highly warranted.
\end{abstract}

Keywords Molecular imaging $\cdot$ Fibroblast activation protein $\cdot$ Head and neck cancer $\cdot$ PET

Christian Linz and Roman C. Brands contributed equally to this work.

This article is part of the Topical Collection on Oncology - Head and Neck.

Constantin Lapa

constantin.lapa@uk-augsburg.de

Extended author information available on the last page of the article

\section{Introduction}

Oral squamous cell carcinoma (OSCC) is the sixth most common tumor entity worldwide and the ninth most frequent cause of death $[1,2]$. With an estimated incidence of about 275,000 cases per year, it accounts for more than $90 \%$ of all malignancies of the oral cavity $[3,4]$. Since the presence of cervical lymph node (LN) metastasis is one of the most relevant negative prognostic factors [5-8] and detection of distant metastases shifts therapy from a curative to a palliative approach [9], accurate tumor staging is of paramount importance for adequate treatment choice and estimation of prognosis [10-12]. 
The utility of positron emission tomography/computed tomography (PET/CT) with $\left[{ }^{18} \mathrm{~F}\right]$-fluorodeoxyglucose $\left(\left[{ }^{18} \mathrm{~F}\right]\right.$ FDG) for staging malignancies of the head and neck is well documented [13-18]. However, specificity of $\left[{ }^{18} \mathrm{~F}\right] \mathrm{FDG}$ is hampered by uptake in inflammatory cells such as neutrophils or macrophages [19]. Since inflammatory processes are very common in head and neck tumors [20], there is an urgent need for a more specific alternative to $\left[{ }^{18} \mathrm{~F}\right] \mathrm{FDG}$ to further improve preoperative staging and therapy of OSCC.

Cancer-associated fibroblasts (CAF) are located within the tumor stroma and modulate the tumor microenvironment by secretion of cytokines, chemokines and growth factors. In OSCC, tumor invasion is promoted by the communication between CAF and tumor cells [21,22]. A particularity of $\mathrm{CAF}$ is the overexpression of fibroblast activation protein $\alpha$ (FAP) which corresponds to a type II transmembrane glycoprotein and acts as a serine protease of the dipeptidylpeptidase family [22, 23]. FAP overexpression on CAF of the tumor microenvironment has been confirmed in more than $90 \%$ of epithelial carcinomas, including malignancies of the breast, lung, colon and head and neck [22, 24, 25]. In contrast, FAP is nearly absent in normal adult tissues [26, 27], rendering it a rather specific target for tumor imaging. Recently, FAP-targeted radioligands that act as FAP inhibitors (FAPI) have become available for PET/CT imaging [28]. And whereas its initially anticipated excellent specificity has been partially relativized by high tracer uptake in non-malignant inflammatory processes [29-33], FAP-directed PET/CT might prove a suitable tool for staging of OSCC.

The aim of this pilot study was to investigate the feasibility of staging newly diagnosed, treatment-naïve OSCC patients using $\left[{ }^{68} \mathrm{Ga}\right] \mathrm{FAPI}-04$ (FAP-directed) PET/CT, and to compare its diagnostic performance with that of $\left[{ }^{18} \mathrm{~F}\right] \mathrm{FDG}$ $\mathrm{PET} / \mathrm{CT}$ and cervical magnetic resonance imaging (MRI).

\section{Methods}

\section{Patients and staging}

Between July 2018 and March 2020, ten consecutive patients ( 8 males, 2 females; mean age, $62 \pm 9$ years) with newly diagnosed, biopsy-proven, treatment-naïve OSCC underwent whole-body $\left[{ }^{18} \mathrm{~F}\right] \mathrm{FDG}$ PET/CT and cervical MRI for primary staging. In addition, FAP-directed PET/CT was performed within a median interval of 4 days (range, $2-16$ days). Within two weeks after imaging all patients underwent surgery according to institutional standards of care. Surgical treatment consisted of resecting the local primary tumor and performing a selective (levels I-III, levels I-III and Va, or levels II, III, and Va) or a complete neck dissection of levels I-V according to Robbins' classification
[34]. Resected primary tumors and lymph nodes were histopathologically assessed for the presence of tumor cells.

${ }^{68} \mathrm{Ga}$-FAPI-04 was administered on a compassionate use basis, in compliance with $\$ 37$ of Declaration of Helsinki and the German Medicinal Products Act, AMG $\S 132 \mathrm{~b}$. Written, informed consent was obtained from all subjects. Data analysis was revealed to the local institutional review board of the University of Würzburg that approved of this study $(2,020,100,201)$.

\section{PET/CT and MR imaging}

Imaging was performed on an integrated PET/CT scanner (Siemens Biograph mCT 64, Siemens Healthineers, Knoxville, USA). Prior to $\left[{ }^{18}\right.$ F]FDG PET/CT imaging, patients fasted for at least $4 \mathrm{~h}$ with blood glucose levels below $160 \mathrm{mg} / \mathrm{dl}$; for FAP-directed imaging no dedicated preparation was required. Mean injected activity was $269 \pm 43 \mathrm{MBq}$ (range, $204-317 \mathrm{MBq}$ ) for $\left[{ }^{18} \mathrm{~F}\right] \mathrm{FDG}$, and $119 \pm 34 \mathrm{MBq}$ (range, $66-168 \mathrm{MBq}$ ) for [ $\left.{ }^{68} \mathrm{Ga}\right] \mathrm{FAPI}-04$, respectively. There were no adverse or clinically detectable pharmacological effects in any of the 10 subjects. No significant changes in vital signs or the results of laboratory studies or electrocardiograms were observed. Whole-body (top of the skull to knees) PET scans were performed one hour after administration of the radiopharmaceutical.

PET emission data were acquired in 3D-mode with a $200 \times 200$ matrix with 2 min emission time per bed position from the vertex of the skull to the proximal thighs. As part of $\left[{ }^{18} \mathrm{~F}\right] \mathrm{FDG}$ PET/CT, transmission data were acquired using contrast-enhanced spiral CT (dose modulation with a quality reference of $180 \mathrm{mAs}, 120 \mathrm{kV}$, a $512 \times 512$ matrix, $5 \mathrm{~mm}$ slice thickness, increment of $30 \mathrm{~mm} / \mathrm{s}$, rotation time of $0.5 \mathrm{~s}$, and pitch index of 1.4). Furthermore, a dedicated acquisition of the head and neck with one bed position, 3 min emission time, and contrast-enhanced CT was performed (180 mAs, $120 \mathrm{kV}$, a $512 \times 512$ matrix, $3 \mathrm{~mm}$ slice thickness, increment of $30 \mathrm{~mm} / \mathrm{s}$, rotation time of $1.0 \mathrm{~s}$, and pitch index of 0.9 ). For anatomical co-registration of the FAP-directed scan, a non-contrast enhanced CT protocol with Care Dose 4D and a quality reference of $80-120 \mathrm{mAs}$ was used.

All PET data were reconstructed iteratively (3 iterations, 24 subsets, Gaussian filtering of $2.0 \mathrm{~mm}$ full width at half maximum) with attenuation correction using dedicated standard software (HD. PET, Siemens Esoft, Siemens Healthineers, Erlangen, Germany).

MRI scans of the head and neck area were acquired using a 1.5 T scanner (Siemens Magnetom Avanto fit, Siemens Healthcare, Erlangen, Germany) or a 3.0 T scanner (Siemens Magnetom Prisma or Skyra, Siemens Healthcare, Erlangen, Germany) with a 64-channel head/neck coil for signal reception. Various T1, T2 and diffusion weighted sequences were 
done with and without contrast agent (Dotagraf; Jenapharm GmbH \& Co. KG, Jena, Germany).

\section{Image analysis}

Three experienced nuclear medicine physicians (AD, OK and $\mathrm{CL}$ ) blinded to all clinical data independently rated all PET/CT scans in random order and at two time points on a syngo.via workstation (Siemens Healthineers, Erlangen, Germany). Foci of increased tracer uptake with reference to normal tissue and blood pool and/or the presence of morphological alterations on CT images were recorded as being positive for tumor involvement. The localization, expansion, and infiltration of osseous structures as well as the presence and number of nodal metastases were recorded for each cervical lymph node level. Lymph node levels were assessed according to the imaging-based nodal classification [12]. Furthermore, whole-body scans were evaluated for distant nodal and organ metastasis and for secondary malignancies. Any initial difference of rating between the three readers was resolved by subsequent consensus reading. Maximum and peak (defined as average activity concentration within a 1 $\mathrm{cm}^{3}$ spherical VOI centered on the "hottest" voxel) standardized uptake values $\left(\mathrm{SUV}_{\max }\right.$ and $\mathrm{SUV}_{\text {peak }}$ ) of the primary tumor, and suspected LN metastases were measured.

MRI scans were evaluated by two experienced board-certified radiologists ( $\mathrm{AD}$ and $\mathrm{OK}$ ) according to previously published methods [35, 36]. Lymph node levels were assessed according to the imaging-based nodal classification [37, 38].

\section{Histopathological analysis}

Specimens were analyzed with regard to tumor size, lymph node metastases, lymph vessel- and venous invasion, perineural infiltration, resection status, and tumor grading according to the TNM classification of OSCC [12].

Immunohistochemistry (IHC) for FAP (antibody ab207178, Abcam, 1:250) was performed on formalinfixed paraffin-embedded tissue slides according to standard IHC protocols. Immunostaining was scored as previously described [39, 40]. In brief, semi-quantitative analysis of stromal staining was scored as 0 (no staining), $1+(1-10 \%)$, $2+(11-50 \%)$, and $3+(51-100 \%$ stromal staining $)$. Tumor-free lymph nodes served as negative controls.

\section{Statistical analysis}

Statistical analyses were performed using the statistics software SPSS (version 24.0; IBM Armonk, US) and R (R v3.6.1, http://www.R-project.org/). Quantitative values are displayed as mean \pm standard deviation or median and range, as appropriate. Spearman's Rho correlation analysis was used to compare uptake of both tracers in corresponding tumors/lymph nodes. McNemar's exact test was used to compare sensitivity and specificity of both tracers and MRI. $P$ values $\leq 0.05$ were considered statistically significant.

\section{Results}

\section{Tumor localization and staging}

Five patients suffered from a primary tumor of the floor of the mouth (two central, three lateral), two subjects from a unilateral primary of the tongue. The mandibular mucosa was affected in two instances, the maxillary in the remaining case. Mean size of the primary lesion was $28.3 \pm 12.9 \mathrm{~mm}$ (range, $11.0-46.0 \mathrm{~mm}$ ), resulting in a T-stage of $\mathrm{T} 2 \mathrm{in}$ five patients, $\mathrm{T} 3$ in two subjects and $\mathrm{T} 4$ in the remaining three patients, respectively. A total of 434 lymph nodes were resected, of which $3.7 \%$ (16/434) harbored metastatic disease in seven patients. The mean size of $\mathrm{LN}$ metastases was $11.4 \pm 9.7 \mathrm{~mm}$ (median, $9 \mathrm{~mm}$; range, $2.0-43.0 \mathrm{~mm}$ ). Neither distant hematologic spread nor second malignancy was observed in this cohort. Details are given in Table 1.

\section{$\left[{ }^{18} \mathrm{~F}\right]$ FDG PET/CT}

On a per-patient analysis $\left[{ }^{18} \mathrm{~F}\right] \mathrm{FDG}$ PET/CT detected all primary tumors with a mean $\mathrm{SUV}_{\text {max }}$ and $\mathrm{SUV}_{\text {peak }}$ of $25.5 \pm 13.2$ (range, $9.6-48.1$ ) and $16.1 \pm 10.3$ (range, 5.1 -34.0 ), respectively. $85.7 \%$ (6/7) of patients with LN metastases were correctly identified.

On a per-lesion basis $\left[{ }^{18} \mathrm{~F}\right] \mathrm{FDG}$ PET/CT revealed $87.5 \%$ (14/16) of LN metastases with a mean $\mathrm{SUV}_{\text {max }}$ and $\mathrm{SUV}_{\text {peak }}$ of $14.9 \pm 12.3$ (range, $2.9-40.6$ ) and $8.3 \pm 6.8$ (range, 1.8 - 25.2), respectively, while the remaining $2 / 16$ (12.5\%; patients \#4 and \#8) were false negative. Of note, the LN metastases missed by $\left[{ }^{18} \mathrm{~F}\right] \mathrm{FDG}$ PET/CT were each only five $\mathrm{mm}$ or less in size. Three out of $17 \mathrm{LNs}$ that were rated as PET-positive turned out to be false positive. Thus, sensitivity and specificity for detection of LN metastases were $87.5 \%$ and $81.3 \%$, respectively. Details are given in Table 2.

\section{FAP-directed PET/CT}

On a per-patient basis FAP-directed PET/CT correctly identified all primary tumors with a mean $\mathrm{SUV}_{\text {max }}$ and $\mathrm{SUV}_{\text {peak }}$ of $20.8 \pm 6.4$ (range, $7.0-29.1$ ) and $13.8 \pm 3.9$ (range, 5.5 - 18.6), respectively, which was comparable to the values derived for FDG PET $\left(r_{s}=0.56, P=0.09\right.$ and $r_{s}=0.84$, $P=0.002$, respectively). Six out of seven patients with LN metastases were correctly identified.

On a per-lesion basis FAP-directed PET/CT detected 81.3\% (13/16) of LN metastases with a mean $\mathrm{SUV}_{\max }$ and a SUV $_{\text {peak }}$ of $10.7 \pm 6.9$ (range, $3.1-25.2$ ) and $6.4 \pm 3.3$ 
Table 1 Patients' characteristics

\begin{tabular}{|c|c|c|c|c|c|c|c|c|c|c|c|c|}
\hline \multirow[t]{2}{*}{ Pat \# } & \multirow[t]{2}{*}{ Age } & \multirow[t]{2}{*}{ Sex } & \multicolumn{5}{|l|}{ Primary Tumor } & \multicolumn{3}{|c|}{ Lymph nodes } & \multicolumn{2}{|c|}{ Distant Mets } \\
\hline & & & Location & Side & Size $[\mathrm{mm}]$ & $\begin{array}{l}\text { Osseous } \\
\text { arrosion / } \\
\text { infiltration }\end{array}$ & T-Stage & Resected & Mets & N-Stage & & M-Stage \\
\hline 1 & 64 & M & alveolar process of the mandible & bilateral & 15 & yes & 2 & 59 & 4 & $3 b$ & none & 0 \\
\hline 2 & 54 & M & floor of the mouth & right & 42 & yes & 3 & 50 & 3 & $3 b$ & none & 0 \\
\hline 3 & 66 & M & floor of the mouth & bilateral & 32 & no & 2 & 36 & 0 & 0 & none & 0 \\
\hline 4 & 49 & M & floor of the mouth & right & 34 & no & 2 & 53 & 1 & 1 & none & 0 \\
\hline 5 & 56 & $\mathrm{~F}$ & tongue & right & 46 & no & 3 & 47 & 1 & $2 \mathrm{a}$ & none & 0 \\
\hline 6 & 60 & M & floor of the mouth & right & 21 & no & 2 & 23 & 0 & 0 & none & 0 \\
\hline 7 & 58 & M & floor of the mouth & bilateral & 27 & yes & 4 & 49 & 1 & $2 \mathrm{a}$ & none & 0 \\
\hline 8 & 80 & $\mathrm{~F}$ & maxillary mucosa & right & 42 & yes & 4 & 46 & 4 & $2 b$ & none & 0 \\
\hline 9 & 62 & M & tongue & right & 13 & no & 2 & 14 & 0 & 0 & none & 0 \\
\hline 10 & 72 & M & alveolar process of the mandible & right & 11 & yes & 4 & 57 & 2 & $3 b$ & none & 0 \\
\hline
\end{tabular}

F, female; LN, lymph node; Mets, metastases; M, male; Pat, patient

Table 2 Individual PET results and immunohistochemical FAP expression of lymph node metastases

\begin{tabular}{|c|c|c|c|c|c|c|c|c|}
\hline \multirow[t]{2}{*}{ Pat\# } & \multirow{2}{*}{$\begin{array}{l}\text { LN [Mets/ } \\
\text { resected] }\end{array}$} & \multirow{2}{*}{$\begin{array}{l}\text { Location } \\
\text { [Side / } \\
\text { Level] }\end{array}$} & \multirow[t]{2}{*}{ Size $[\mathrm{mm}]$} & \multicolumn{2}{|c|}{$\left[{ }^{18} \mathrm{~F}\right] \mathrm{FDG}$ PET } & \multicolumn{2}{|c|}{ FAP-directed PET } & \multirow{2}{*}{$\begin{array}{l}\text { IHC } \\
\text { FAP CAF }\end{array}$} \\
\hline & & & & $\mathrm{SUV}_{\max }$ & $\mathrm{SUV}_{\text {peak }}$ & $\mathrm{SUV}_{\max }$ & $\mathrm{SUV}_{\text {peak }}$ & \\
\hline \multirow[t]{4}{*}{1} & \multirow[t]{4}{*}{$4 / 59$} & $\mathrm{R} / \mathrm{Ib}$ & 11 & 10 & 3 & 8 & 5 & $2+$ \\
\hline & & $\mathrm{R} / \mathrm{Ia}$ & 5 & 3 & 2 & 3 & 2 & $2+$ \\
\hline & & $\mathrm{L} / \mathrm{Ia}$ & 2 & 3 & 2 & $\mathrm{n} / \mathrm{d}$ & $\mathrm{n} / \mathrm{d}$ & $3+$ \\
\hline & & $\mathrm{L} / \mathrm{Ib}$ & 6 & 7 & 4 & 5 & 3 & $3+$ \\
\hline \multirow[t]{3}{*}{2} & \multirow[t]{3}{*}{$3 / 50$} & $\mathrm{R} / \mathrm{Ib}$ & 11 & 8 & 5 & 8 & 5 & $2+$ \\
\hline & & $\mathrm{R} / \mathrm{Ib}$ & 9 & 5 & 3 & 6 & 4 & $2+$ \\
\hline & & R / IIa & 12 & 7 & 5 & 8 & 6 & $3+$ \\
\hline 3 & $0 / 36$ & & & & & & & \\
\hline 4 & $1 / 53$ & R / IIa & 5 & $\mathrm{n} / \mathrm{d}$ & $\mathrm{n} / \mathrm{d}$ & $\mathrm{n} / \mathrm{d}$ & $\mathrm{n} / \mathrm{d}$ & $2+$ \\
\hline 5 & $1 / 47$ & R / IIa & 43 & 21 & 13 & 13 & 8 & $2+$ \\
\hline 6 & $0 / 23$ & & & & & & & \\
\hline 7 & $1 / 49$ & $\mathrm{R} / \mathrm{Ib}$ & 9 & 5 & 5 & 6 & 4 & $3+$ \\
\hline \multirow[t]{4}{*}{8} & \multirow[t]{4}{*}{$4 / 46$} & $\mathrm{R} / \mathrm{Ib}$ & 22 & 34 & 17 & 20 & 11 & $3+$ \\
\hline & & $\mathrm{R} / \mathrm{Ib}$ & 5 & $\mathrm{n} / \mathrm{d}$ & $\mathrm{n} / \mathrm{d}$ & $\mathrm{n} / \mathrm{d}$ & $\mathrm{n} / \mathrm{d}$ & $2+$ \\
\hline & & R / IIa & 8 & 16 & 8 & 8 & 6 & $1+$ \\
\hline & & R / IIb & 8 & 20 & 12 & 8 & 6 & $2+$ \\
\hline 9 & $0 / 14$ & & & & & & & \\
\hline \multirow[t]{2}{*}{10} & \multirow[t]{2}{*}{$2 / 57$} & $\mathrm{R} / \mathrm{Ib}$ & 12 & 41 & 25 & 20 & 14 & $3+$ \\
\hline & & R / IIa & 15 & 29 & 12 & 25 & 9 & $2+$ \\
\hline
\end{tabular}

CAF, cancer-associated fibroblasts; FAP, fibroblast activation protein; IHC, immunohistochemistry; L, left; n/d, not detected; R, right; LN, lymph node; Mets, metastases; SUV, standardized uptake value (range, 2.4 - 13.8), respectively. The remaining 3/16 LN metastases (18.8\%; patients \#1, \#4 and \#8) with a respective LN size of $2 \mathrm{~mm}$ (patient \#1) and $5 \mathrm{~mm}$ (patients \#4 and \#8) were missed. One of $14 \mathrm{LNs}$ that were rated to be suspicious for metastatic disease turned out to be false positive, resulting in a sensitivity and specificity for the detection of LN metastases of $81.3 \%$ and $93.3 \%$, respectively. Examples of FAP-directed imaging results are displayed in Figs. 1 and 2.

\section{MRI}

On a per-patient basis MRI correctly identified all primary tumors and six out of seven patients with LN metastases. Of note, one of the patients with lymph node metastasis (patient \#4) was rated positive due to a false positive LN, while the true metastasis was rated FN. 


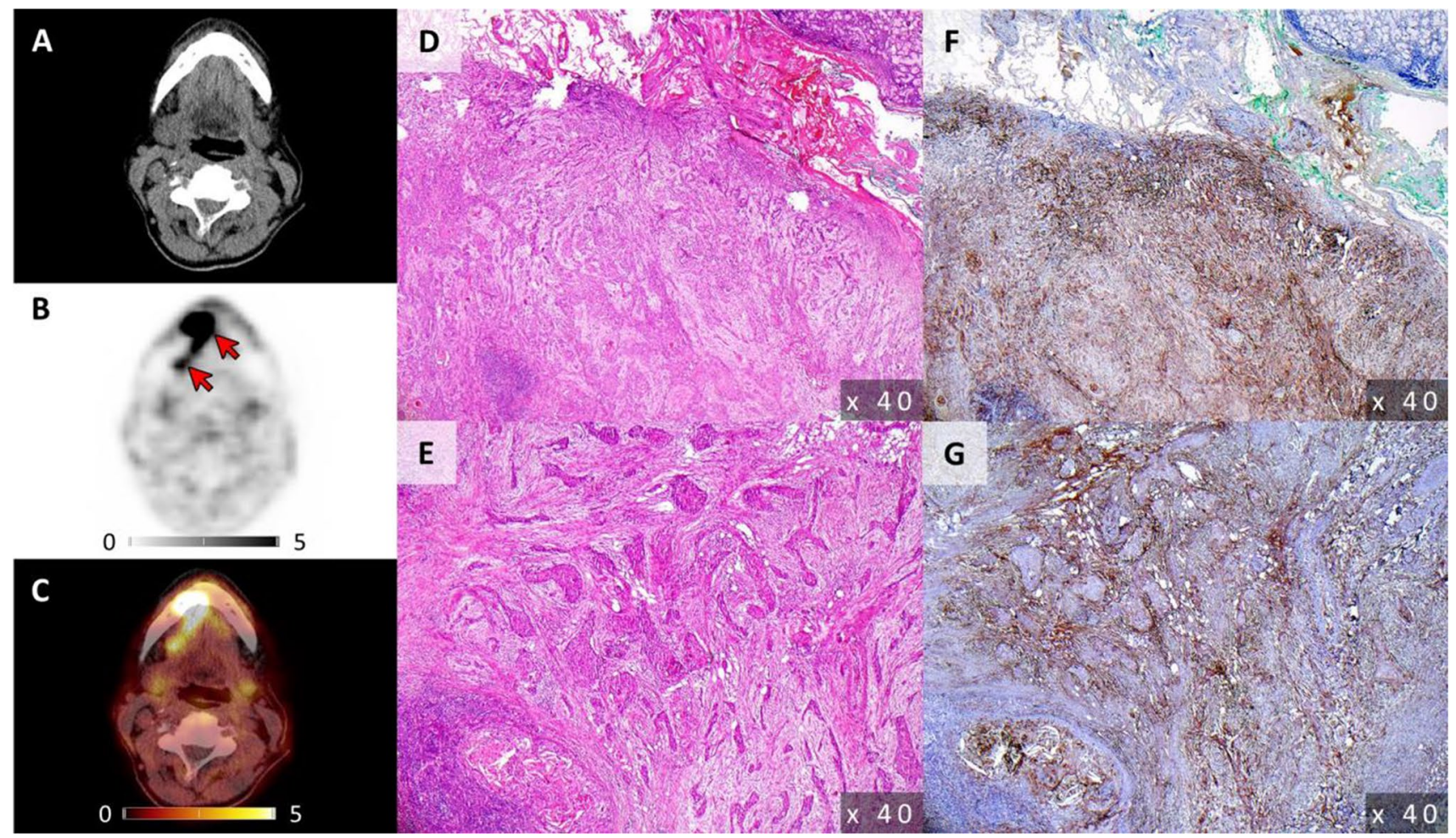

Fig. 1 Example of FAP-directed imaging and respective immunohistochemistry of both primary tumor and cervical lymph node metastasis in a patient with newly diagnosed, treatment-naïve oral squamous cell carcinoma. Computed tomography $(\mathrm{CT}, \mathbf{A})$, fibroblast activation protein (FAP)-directed positron emission tomography (PET, B) as well as hybrid PET/CT imaging (C) in a patient with newly diag-

On a per-lesion basis MRI detected 50.0\% (8/16) of LN metastases. The remaining $8 / 16 \mathrm{LN}$ metastases $(50.0 \%$; patients \#1, \#4, \#7, \#8 and \#9) with a respective LN size between 2 and $12 \mathrm{~mm}$ were missed. Five of $13 \mathrm{LNs}$ that were rated to be suspicious for metastatic disease turned out to be false positive, resulting in a sensitivity and specificity for the detection of LN metastases of $50.0 \%$ and $61.5 \%$, respectively. However, it must be noted that there were significant imaging artefacts in four subjects $(\# 4, \# 5, \# 7$ and \#10), particularly due to metal implants (patients \#4, \#5 and \#7) and patient movement (patients \#4 and \#10).

\section{Immunohistochemistry}

All primary tumors and all lymph node metastases showed a variable target expression with $15 / 16$ cases demonstrating positive FAP immunostaining in $>10 \%-50 \%$ (score $2+$; $56 \%$ ) and $>50 \%$ of surrounding stromal cells (score $3+$; $38 \%)$. FAP expression was also confirmed in the metastases missed by FAP-directed PET/CT (patients \#1, \#4 and \#8). Individual IHC results for FAP for both primary lesions and LN metastases are given in Table 3. nosed, treatment-naïve squamous cell carcinoma of the alveolar process of the mandible (patient \#1) depicts both the primary tumor as well as an adjacent cervical lymph node metastasis (arrows). Histological work-up (D-G) including immunohistochemistry for FAP (F, G) could confirm presence of FAP-positive disease in both instances (primary tumor: D, F; lymph node metastasis: $\mathbf{E}, \mathbf{G}$ )

In addition to the reactivity in CAF, we also observed a reactivity of variable quantity and intensity, but mostly weaker than in the CAF, in the cytoplasm and / or on the cell surface of the tumor cells in a subset of samples.

\section{Discussion}

In this pilot study in patients with newly diagnosed, treatment-naïve OSCC, CAF-directed molecular imaging showed promise as a feasible diagnostic alternative to standard $\left[{ }^{18} \mathrm{~F}\right]$ FDG PET/CT.

Due to the high glucose consumption of tumor cells, $\left[{ }^{18} \mathrm{~F}\right]$ FDG is the reference tool for molecular imaging of squamous cell carcinoma of the head and neck and has proven its clinical value in a number of trials with high sensitivity and acceptable specificity [13-18, 41]. A recent multi-center trial including 23 different imaging sites in the US prospectively evaluated the value of $\left[{ }^{18} \mathrm{~F}\right] \mathrm{FDG}$ PET/CT in patients with newly diagnosed, first-time, head and neck squamous cell carcinoma and confirmed the high negative predictive value of this imaging modality [42]. 


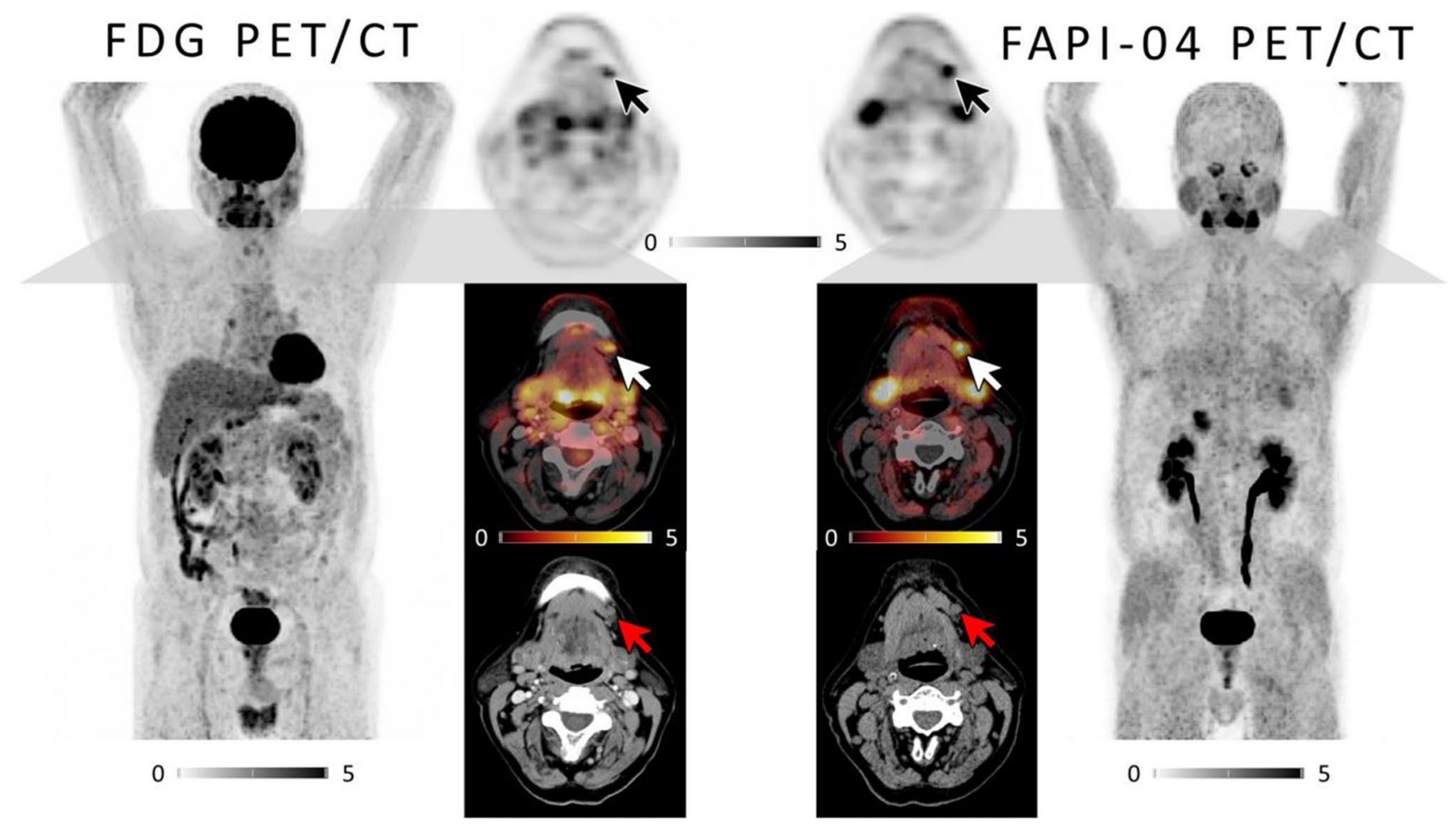

Fig. 2 Comparison of $\left[{ }^{18}\right.$ F]FDG and FAP-directed $\left[{ }^{68}\right.$ Ga]FAPI-04 $\mathrm{PET} / \mathrm{CT}$ in a patient with newly diagnosed, treatment-naïve oral squamous cell carcinoma and a cervical lymph node metastasis. Maximum Intensity Projections (MIP, outer columns) as well as axial PET (top), fused PET/CT (middle) and CT (bottom) slices of $\left[{ }^{18} \mathrm{~F}\right] \mathrm{FDG}$ (left) and [ $\left.{ }^{68} \mathrm{Ga}\right]$ FAPI 04 (right) PET scans in a patient with newly

In our cohort, $\left[{ }^{18} \mathrm{~F}\right] \mathrm{FDG} \mathrm{PET} / \mathrm{CT}$ detected all primary tumors and most lymph node metastases with a sensitivity of $87.5 \%$ and a specificity of $81.3 \%$, which is in line with the body of literature including a recent meta-analysis [16, $42,43]$. It is worth mentioning that the lymph node metastases missed by $\left[{ }^{18} \mathrm{~F}\right]$ FDG PET/CT had a size of $5 \mathrm{~mm}$ or smaller, which is at the limit of the system's technical image resolution.

Molecular imaging with [ $\left.{ }^{68} \mathrm{Ga}\right]-\mathrm{FAPI}-04$ PET/CT demonstrated identical primary tumor detection. Regarding metastases a slightly lower sensitivity $(81.3 \%)$ as well as a marginally higher specificity $(93.3 \%)$ for cervical lymph node involvement was observed in comparison to $\left[{ }^{18} \mathrm{~F}\right] \mathrm{FDG}$ PET/CT. PET signal intensity as assessed by $\mathrm{SUV}_{\max }$ varied between 7.0 and 29.1 and is in line with recent studies that investigated the diagnostic performance of $\left[{ }^{68} \mathrm{Ga}\right.$ ]FAPI-04 $\mathrm{PET} / \mathrm{CT}$ in head and neck cancer [44]. Compared to cervical MRI both PET tracers demonstrated slight diagnostic advantages, however, it should be taken into account that in almost half of patients (4/10), metal and/or movement artefacts severely impacted MRI image quality.

Presence of FAP on the cell surface of CAFs could be confirmed by IHC in all tumor specimens while it was absent diagnosed, treatment-naïve squamous cell carcinoma of the alveolar process of the mandible (patient \#1). Whereas both tracers detect the regional lymph node metastasis in cervical level Ib, FAP-directed imaging offers higher tracer uptake. Of note, neither tonsils nor other lymph nodes are [ ${ }^{68} \mathrm{Ga}$ ]FAPI-04 PET-positive in this example

in reactive, tumor-free lymph nodes. The high specificity of FAP-directed PET/CT may be particularly helpful in cases with extensive inflammatory changes in the oral cavity, in which $\left[{ }^{18} \mathrm{~F}\right]$ FDG PET/CT faces challenges distinguishing malignant disease from non-specific changes. In this pilot study, only one false-positive lymph node was described in $\left[{ }^{68} \mathrm{Ga}\right] \mathrm{FAPI}-04 \mathrm{PET} / \mathrm{CT}$, as compared to three in $\left[{ }^{18} \mathrm{~F}\right] \mathrm{FDG}$ $\mathrm{PET} / \mathrm{CT}$ and five false-positives in MRI, respectively. Thus, by minimizing the number of neck dissections due to falsepositive cervical lymph nodes, the extent of surgery might be individually tailored and morbidity significantly reduced without jeopardizing oncologic results. However, in view of relatively high physiological tracer uptake of $\left[{ }^{68} \mathrm{Ga}\right]$ FAPI-04 in the oral mucosa [45], and increasing evidence for accumulation also in non-malignant inflammatory processes such as IgG4-related diseases [32, 46], the preliminary results of this pilot study should be taken with caution.

Interestingly, FAP expression in the cytoplasm and / or on the cell surface of the tumor cells could be observed in a subset of samples. This might be a non-specific reaction, e.g. to keratinization products; however, epithelial cancer cell expression of FAP has been reported for a variety of cancer entities including oral squamous cell cancer [22, 47]. 


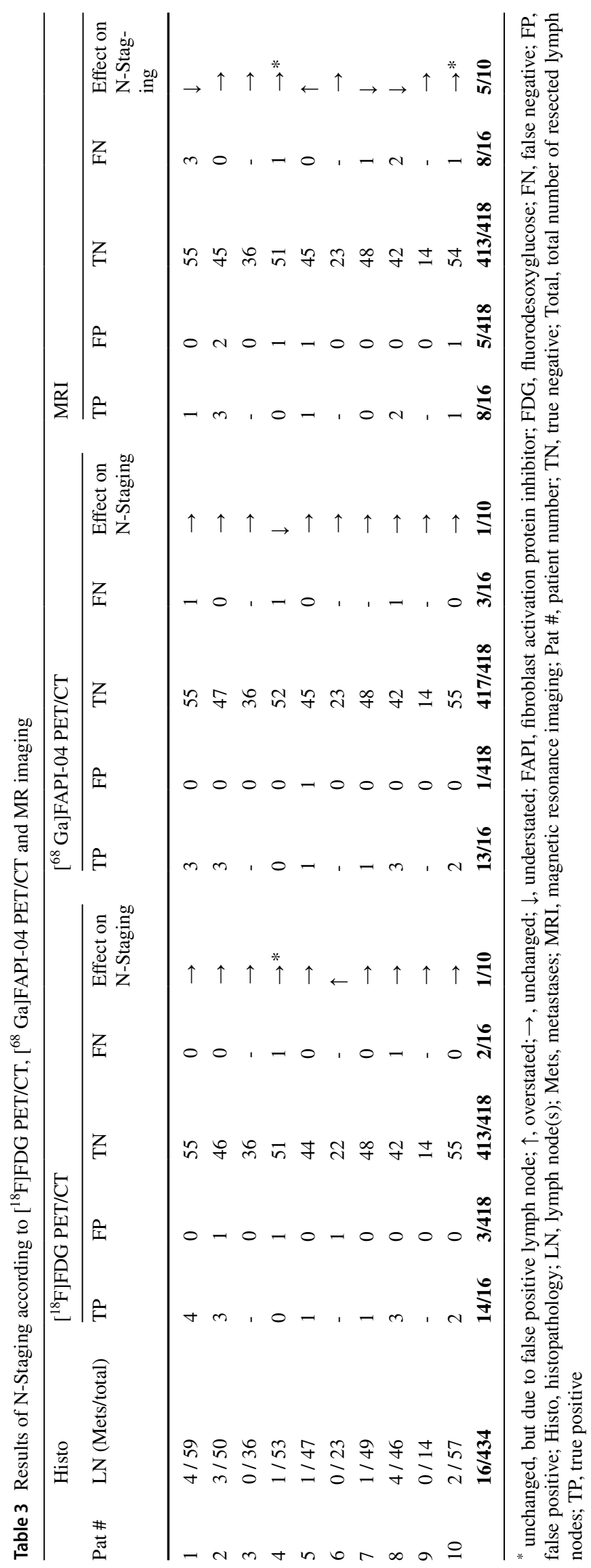


In OSCC, FAP expression could be correlated with tumor size, lymph-node metastasis and shorter overall survival [22]. Whereas the current sample size of our study precludes any firm conclusions, CAF-directed PET/CT imaging might not only address CAF but also directly the tumor cell and serve as a prognostic non-invasive biomarker.

Several limitations of this pilot study need to be mentioned. First, only a small number of patients could be included, thus limiting statistical power of our results. In the cohort analyzed, no distant metastases or second malignancies were encountered, therefore the value of FAP-directed PET/CT in these scenarios could not be investigated. Another limitation could result from physiological tracer uptake of $\left[{ }^{68} \mathrm{Ga}\right]$ FAPI-04 in the oral mucosa, which is comparable to that of $\left[{ }^{18} \mathrm{~F}\right] \mathrm{FDG}[45]$ and might potentially translate into compromised tumor-to-background contrast. However, in our small pilot study no difficulties in distinguishing primary tumor from surrounding tissue were encountered. Last, since no follow-up is available, no conclusion on the prognostic power of the new imaging tool can be drawn and future studies have to investigate whether the reported negative prognostic impact of high FAP expression in OSCC can be non-invasively detected by FAP-directed PET/CT [22].

In contrast, the homogeneous patient cohort with newly diagnosed, treatment-naïve subjects, the direct comparison between $\left[{ }^{18} \mathrm{~F}\right] \mathrm{FDG}$, cervical MRI and FAP-directed PET/ $\mathrm{CT}$ as well as the stringent pathological work-up (of primary tumors and 434 lymph nodes) including IHC are strengths of the current work.

\section{Conclusion}

Given the improved (although not perfect) specificity of FAP-targeted imaging compared with $\left[{ }^{18} \mathrm{~F}\right] \mathrm{FDG},\left[{ }^{68} \mathrm{Ga}\right]$ FAPI-04 (or its successors) may have the potential to prevent overtreatment and to reduce patient morbidity by minimizing the number of neck dissections due to false-positive cervical lymph nodes. However, given the small number of patients enrolled in this pilot study, no firm conclusion can be drawn at the moment, and further evaluation should be based on future large, prospective, multi-center studies.

Supplementary Information The online version contains supplementary material available at https://doi.org/10.1007/s00259-021-05422-z.

Authors' contributions Conceptualization, C.L., R.C.B., A.K.B., C.L.2; Image analysis, O.K., A.D., J.B., S.S., A.K.B., C.L.2., M.K.; Clinical Data Assessment, all authors; Formal analysis, C.L., R.C.B., A.K.B., C.L.2, M.K.; Immunohistochemistry, E.G-H.; Writing—original draft preparation, C.L., R.C.B., S.H., A.S., Y.Z., J.H., C.L.2, M.K.; Writing-review and editing, C.L., R.C.B., O.K., A.D., J.B., E.G-H., S.H., A.S., Y.Z., A.K., C.L.2, M.K
Funding Open Access funding enabled and organized by Projekt DEAL.

Data availability All data will be made available upon request.

Code availability Not applicable.

\section{Declarations}

Ethics approval Data analysis was revealed to the local institutional review board of the University of Würzburg that approved of this study $(2,020,100,201)$.

Consent to participate Written, informed consent was obtained from all subjects.

Consent for publication All authors have read and agreed to the published version of the manuscript.

\section{Conflicts of interest None.}

Open Access This article is licensed under a Creative Commons Attribution 4.0 International License, which permits use, sharing, adaptation, distribution and reproduction in any medium or format, as long as you give appropriate credit to the original author(s) and the source, provide a link to the Creative Commons licence, and indicate if changes were made. The images or other third party material in this article are included in the article's Creative Commons licence, unless indicated otherwise in a credit line to the material. If material is not included in the article's Creative Commons licence and your intended use is not permitted by statutory regulation or exceeds the permitted use, you will need to obtain permission directly from the copyright holder. To view a copy of this licence, visit http://creativecommons.org/licenses/by/4.0/.

\section{References}

1. Hernandez-Guerrero JC, Jacinto-Aleman LF, Jimenez-Farfan MD, Macario-Hernandez A, Hernandez-Flores F, Alcantara-Vazquez A. Prevalence trends of oral squamous cell carcinoma. Mexico City's General Hospital experience. Med Oral Patol Oral Cir Bucal. 2013;18:e306-11.

2. Sadick M, Schoenberg SO, Hoermann K, Sadick H. Current oncologic concepts and emerging techniques for imaging of head and neck squamous cell cancer. GMS Curr Topics Otorhinolaryngol Head Neck Surg. 2012;11:Doc08. https://doi.org/10.3205/cto00 0090.

3. Bagan J, Sarrion G, Jimenez Y. Oral cancer: clinical features. Oral Oncol. 2010;46:414-7. https://doi.org/10.1016/j.oraloncolo gy.2010.03.009.

4. Tandon P, Dadhich A, Saluja H, Bawane S, Sachdeva S. The prevalence of squamous cell carcinoma in different sites of oral cavity at our Rural Health Care Centre in Loni, Maharashtra - a retrospective 10-year study. Contemp Oncol (Pozn). 2017;21:178-83. https://doi.org/10.5114/wo.2017.68628.

5. DiTroia JF. Nodal metastases and prognosis in carcinoma of the oral cavity. Otolaryngol Clin North Am. 1972;5:333-42.

6. Kumar T, Patel MD. Pattern of lymphatic metastasis in relation to the depth of tumor in oral tongue cancers: a clinico pathological correlation. Indian J Otolaryngol Head Neck Surg. 2013;65:5963. https://doi.org/10.1007/s12070-012-0504-y. 
7. Sparano A, Weinstein G, Chalian A, Yodul M, Weber R. Multivariate predictors of occult neck metastasis in early oral tongue cancer. Otolaryngol Head Neck Surg. 2004;131:472-6. https:// doi.org/10.1016/j.otohns.2004.04.008.

8. Teichgraeber JF, Clairmont AA. The incidence of occult metastases for cancer of the oral tongue and floor of the mouth: treatment rationale. Head Neck Surg. 1984;7:15-21.

9. Haigentz M Jr, Hartl DM, Silver CE, Langendijk JA, Strojan P, Paleri V, et al. Distant metastases from head and neck squamous cell carcinoma Part III. Treat Oral Oncol. 2012;48:787-93. https:// doi.org/10.1016/j.oraloncology.2012.03.019.

10. de Bree R, Castelijns JA, Hoekstra OS, Leemans CR. Advances in imaging in the work-up of head and neck cancer patients. Oral Oncol. 2009;45:930-5. https://doi.org/10.1016/j.oraloncology. 2009.07.011.

11. Edge SB, Compton CC. The American joint committee on cancer: the 7th edition of the AJCC cancer staging manual and the future of TNM. Ann Surg Oncol. 2010;17:1471-4. https://doi.org/10. 1245/s10434-010-0985-4.

12. Huang SH, O'Sullivan B. Overview of the 8th Edition TNM classification for head and neck cancer. Curr Treat Options Oncol. 2017;18:40. https://doi.org/10.1007/s11864-017-0484-y.

13. Cho JK, Ow TJ, Lee AY, Smith RV, Schlecht NF, Schiff BA, et al. Preoperative (18)F-FDG-PET/CT vs contrast-enhanced CT to identify regional nodal metastasis among patients with head and neck squamous cell carcinoma. Otolaryngol Head Neck Surg. 2017;157:439-47. https://doi.org/10.1177/0194599817703927.

14. Dammann F, Horger M, Mueller-Berg M, Schlemmer H, Claussen $\mathrm{CD}$, Hoffman J, et al. Rational diagnosis of squamous cell carcinoma of the head and neck region: comparative evaluation of CT, MRI, and 18FDG PET. AJR Am J Roentgenol. 2005;184:132631. https://doi.org/10.2214/ajr.184.4.01841326.

15. Hirshoren N, Olayos E, Herschtal A, Ravi Kumar AS, Gyorki DE. Preoperative positron emission tomography for node-positive head and neck cutaneous squamous cell carcinoma. Otolaryngol Head Neck Surg. 2018;158:122-6. https://doi.org/10.1177/0194599817 731735.

16. Krabbe CA, Balink H, Roodenburg JL, Dol J, de Visscher JG. Performance of 18F-FDG PET/contrast-enhanced CT in the staging of squamous cell carcinoma of the oral cavity and oropharynx. Int J Oral Maxillofac Surg. 2011;40:1263-70. https://doi.org/10. 1016/j.ijom.2011.06.023.

17. Subramaniam RM, Agarwal A, Colucci A, Ferraro R, Paidpally V, Mercier G. Impact of concurrent diagnostic level CT with PET/CT on the utilization of stand-alone CT and MRI in the management of head and neck cancer patients. Clin Nucl Med. 2013;38:790-4. https://doi.org/10.1097/RLU.0b013e31829f8ca5.

18. Wallowy P, Diener J, Grunwald F, Kovacs AF. 18F-FDG PET for detecting metastases and synchronous primary malignancies in patients with oral and oropharyngeal cancer. Nuklearmedizin. 2009;48:192-9; quiz N42. https://doi.org/10.3413/nukmed-0242.

19. Kircher M, Lapa C. Infection and inflammation imaging: beyond FDG. PET Clin. 2020;15:215-29. https://doi.org/10.1016/j.cpet. 2019.11.004.

20. Plaxton NA, Brandon DC, Corey AS, Harrison CE, KaragulleKendi AT, Halkar RK, et al. Characteristics and limitations of FDG PET/CT for imaging of squamous cell carcinoma of the head and neck: a comprehensive review of anatomy, metastatic pathways, and image findings. AJR Am J Roentgenol. 2015;205:W519-31. https://doi.org/10.2214/AJR.14.12828.

21. Bae JY, Kim EK, Yang DH, Zhang X, Park YJ, Lee DY, et al. Reciprocal interaction between carcinoma-associated fibroblasts and squamous carcinoma cells through interleukin-1alpha induces cancer progression. Neoplasia. 2014;16:928-38. https://doi.org/ 10.1016/j.neo.2014.09.003.
22. Wang H, Wu Q, Liu Z, Luo X, Fan Y, Liu Y, et al. Downregulation of FAP suppresses cell proliferation and metastasis through PTEN/PI3K/AKT and Ras-ERK signaling in oral squamous cell carcinoma. Cell Death Dis. 2014;5:e1155. https://doi.org/10.1038/ cddis.2014.122.

23. Scanlan MJ, Raj BK, Calvo B, Garin-Chesa P, Sanz-Moncasi MP, Healey JH, et al. Molecular cloning of fibroblast activation protein alpha, a member of the serine protease family selectively expressed in stromal fibroblasts of epithelial cancers. Proc Natl Acad Sci U S A. 1994;91:5657-61. https://doi.org/10.1073/pnas. 91.12.5657.

24. Garin-Chesa P, Old LJ, Rettig WJ. Cell surface glycoprotein of reactive stromal fibroblasts as a potential antibody target in human epithelial cancers. Proc Natl Acad Sci U S A. 1990;87:7235-9. https://doi.org/10.1073/pnas.87.18.7235.

25. Brennen WN, Isaacs JT, Denmeade SR. Rationale behind targeting fibroblast activation protein-expressing carcinoma-associated fibroblasts as a novel chemotherapeutic strategy. Mol Cancer Ther. 2012;11:257-66. https://doi.org/10.1158/1535-7163. MCT-11-0340.

26. Liu F, Qi L, Liu B, Liu J, Zhang H, Che D, et al. Fibroblast activation protein overexpression and clinical implications in solid tumors: a meta-analysis. PLoS ONE. 2015;10:e0116683. https:// doi.org/10.1371/journal.pone.0116683.

27. Niedermeyer J, Garin-Chesa P, Kriz M, Hilberg F, Mueller E, Bamberger U, et al. Expression of the fibroblast activation protein during mouse embryo development. Int J Dev Biol. 2001;45:445-7.

28. Lindner T, Loktev A, Altmann A, Giesel F, Kratochwil C, Debus $\mathrm{J}$, et al. Development of quinoline-based theranostic ligands for the targeting of fibroblast activation protein. J Nucl Med. 2018;59:1415-22. https://doi.org/10.2967/jnumed.118.210443.

29. Luo Y, Pan Q, Zhang W. IgG4-related disease revealed by (68) Ga-FAPI and (18)F-FDG PET/CT. Eur J Nucl Med Mol Imaging. 2019;46:2625-6. https://doi.org/10.1007/s00259-019-04478-2.

30. Luo Y, Pan Q, Zhang W, Li F. Intense FAPI uptake in inflammation may mask the tumor activity of pancreatic cancer in $68 \mathrm{Ga}-$ FAPI PET/CT. Clin Nucl Med. 2020;45:310-1. https://doi.org/10. 1097/rlu.0000000000002914.

31. Pan Q, Luo Y, Zhang W. Recurrent immunoglobulin G4-related disease shown on 18F-FDG and 68Ga-FAPI PET/CT. Clin Nucl Med. 2020;45:312-3. https://doi.org/10.1097/rlu.0000000000 002919.

32. Schmidkonz C, Rauber S, Atzinger A, Agarwal R, Götz TI, Soare A, et al. Disentangling inflammatory from fibrotic disease activity by fibroblast activation protein imaging. Ann Rheum Dis. 2020;79:1485-91. https://doi.org/10.1136/annrh eumdis-2020-217408.

33. Hao B, Wu X, Pang Y, Sun L, Wu H, Huang W, et al. [(18)F]FDG and $([68) \mathrm{Ga}] \mathrm{Ga}$-DOTA-FAPI-04 PET/CT in the evaluation of tuberculous lesions. Eur J Nucl Med Mol Imaging. 2021;48:6512. https://doi.org/10.1007/s00259-020-04941-5.

34. Robbins KT, Clayman G, Levine PA, Medina J, Sessions R, Shaha A, et al. Neck dissection classification update: revisions proposed by the American head and neck society and the American academy of otolaryngology-head and neck surgery. Arch Otolaryngol Head Neck Surg. 2002;128:751-8.

35. Campbell RS, Baker E, Chippindale AJ, Wilson G, McLean N, Soames JV, et al. MRI T staging of squamous cell carcinoma of the oral cavity: radiological-pathological correlation. Clin Radiol. 1995;50:533-40. https://doi.org/10.1016/s0009-9260(05)83187-3.

36. Trotta BM, Pease CS, Rasamny JJ, Raghavan P, Mukherjee S. Oral cavity and oropharyngeal squamous cell cancer: key imaging findings for staging and treatment planning. Radiographics Rev Publ Radiol Soc North Am Inc. 2011;31:339-354. https://doi.org/ 10.1148/rg.312105107. 
37. Forghani R, Yu E, Levental M, Som PM, Curtin HD. Imaging evaluation of lymphadenopathy and patterns of lymph node spread in head and neck cancer. Expert Rev Anticancer Ther. 2015;15:207-24. https://doi.org/10.1586/14737140.2015.978862.

38. Som PM, Curtin HD, Mancuso AA. Imaging-based nodal classification for evaluation of neck metastatic adenopathy. AJR Am J Roentgenol. 2000;174:837-44. https://doi.org/10.2214/ajr.174.3. 1740837.

39. Henry LR, Lee HO, Lee JS, Klein-Szanto A, Watts P, Ross EA, et al. Clinical implications of fibroblast activation protein in patients with colon cancer. Clin Cancer Res. 2007;13:1736-41. https://doi.org/10.1158/1078-0432.CCR-06-1746.

40. Serfling S, Zhi Y, Schirbel A, Lindner T, Meyer T, Gerhard-Hartmann E, et al. Improved cancer detection in Waldeyer's tonsillar ring by (68)Ga-FAPI PET/CT imaging. Eur J Nucl Med Mol Imaging. 2020. https://doi.org/10.1007/s00259-020-05055-8.

41. Pentenero M, Cistaro A, Brusa M, Ferraris MM, Pezzuto C, Carnino R, et al. Accuracy of 18F-FDG-PET/CT for staging of oral squamous cell carcinoma. Head Neck. 2008;30:1488-96. https:// doi.org/10.1002/hed.20906.

42. Lowe VJ, Duan F, Subramaniam RM, Sicks JD, Romanoff J, Bartel T, et al. Multicenter Trial of [(18)F]fluorodeoxyglucose positron emission tomography/computed tomography staging of head and neck cancer and negative predictive value and surgical impact in the N0 neck: results from ACRIN 6685. J Clin Oncol Off J Am Soc Clin Oncol. 2019;37:1704-12. https://doi.org/10. 1200/jco.18.01182.

43. Yongkui L, Jian L, Wanghan, Jingui L. 18FDG-PET/CT for the detection of regional nodal metastasis in patients with primary head and neck cancer before treatment: a meta-analysis. Surg Oncol. 2013;22:e11-6. https://doi.org/10.1016/j.suronc.2013.02. 002.

44. Syed M, Flechsig P, Liermann J, Windisch P, Staudinger F, Akbaba S, et al. Fibroblast activation protein inhibitor (FAPI) PET for diagnostics and advanced targeted radiotherapy in head and neck cancers. Eur J Nucl Med Mol Imaging. 2020;47:2836-45. https://doi.org/10.1007/s00259-020-04859-y.

45. Giesel FL, Kratochwil C, Lindner T, Marschalek MM, Loktev A, Lehnert W, et al. (68)Ga-FAPI PET/CT: biodistribution and preliminary dosimetry estimate of 2 DOTA-containing FAPtargeting agents in patients with various cancers. J Nucl Med. 2019;60:386-92. https://doi.org/10.2967/jnumed.118.215913.

46. Luo Y, Pan Q, Yang H, Peng L, Zhang W, Li F. Fibroblast activation protein-targeted PET/CT with (68)Ga-FAPI for imaging IgG4-related disease: comparison to (18)F-FDG PET/CT. J Nucl Med. 2021;62:266-71. https://doi.org/10.2967/jnumed.120. 244723.

47. Pure E, Blomberg R. Pro-tumorigenic roles of fibroblast activation protein in cancer: back to the basics. Oncogene. 2018;37:4343-57. https://doi.org/10.1038/s41388-018-0275-3.

Publisher's note Springer Nature remains neutral with regard to jurisdictional claims in published maps and institutional affiliations.

\section{Authors and Affiliations}

\section{Christian Linz ${ }^{1,2} \cdot$ Roman C. Brands $s^{1,2}$. Olivia Kertels ${ }^{2,3} \cdot$ Alexander Dierks ${ }^{2,4,5} \cdot$ Joachim Brumberg ${ }^{2,4,6}$. Elena Gerhard-Hartmann ${ }^{2,7}$. Stefan Hartmann ${ }^{1}$. Andreas Schirbel ${ }^{2,4}$. Sebastian Serfling ${ }^{2,4}$. Yingjun Zhi ${ }^{8}$. Andreas K. Buck ${ }^{2,4} \cdot$ Alexander Kübler ${ }^{1,2} \cdot$ Julian Hohm ${ }^{1}$. Constantin Lapa ${ }^{2,4,5}$ - Malte Kircher ${ }^{2,4,5}$}

1 Department of Oral and Maxillofacial Plastic Surgery, University Hospital of Würzburg, Pleicherwall 2, 97070 Würzburg, Germany

2 Comprehensive Cancer Center Mainfranken, University Hospital of Würzburg, Josef-Schneider-Str. 6, 97080 Würzburg, Germany

3 Institute for Diagnostic and Interventional Radiology, University Hospital of Würzburg, Oberdürrbacherstr. 6, 97080 Würzburg, Germany

4 Department of Nuclear Medicine, University Hospital of Würzburg, Oberdürrbacherstr. 6, 97080 Würzburg, Germany
5 Nuclear Medicine, Medical Faculty, University of Augsburg, Stenglinstraße 2, 86156 Augsburg, Germany

6 Department of Nuclear Medicine, University Hospital of Freiburg, Hugstetter Straße 55, 79106 Freiburg, Germany

7 Department of Pathology, University of Würzburg, Josef-Schneider-Str.2, 97080 Würzburg, Germany

8 Department of Otorhinolaryngology, University Hospital of Würzburg, Josef-Schneider-Str. 11, 97080 Würzburg, Germany 